\title{
Arachnoiditis ossificans in a pediatric patient
}

\author{
Joseph Junewick • Shannon K. Culver
}

Received: 18 May 2009/Revised: 5 June 2009 / Accepted: 24 June 2009 /Published online: 28 July 2009

(C) Springer-Verlag 2009

A 14-year-old girl with spastic quadriplegic cerebral palsy and progressive neuromuscular scoliosis presented with back pain 6 months after posterior spinal fixation. CT of the lumbar spine revealed numerous ossified dural plaques (Fig. 1, arrows). Semitransparent volume-rendered CT reconstruction shows the distribution of intraspinal ossifications (gray amorphous regions with white stippling) in

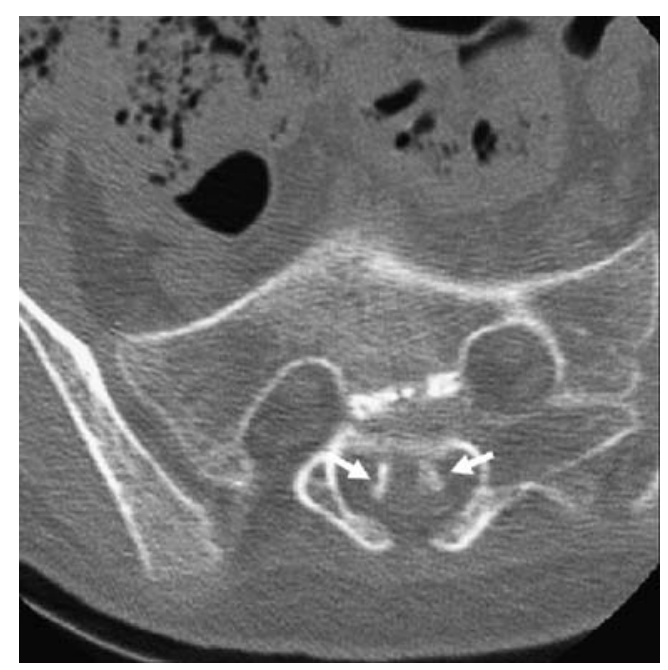

Fig. 1 Axial non-contrast CT image of the spine

J. Junewick $(\bowtie)$

Department of Radiology, DeVos Children's Hospital,

100 Michigan NE,

Grand Rapids, MI 49503, USA

e-mail: jjunewick@comcast.net

J. Junewick

Grand Rapids Division, Advanced Radiology Services, P.C.,

Grand Rapids, MI, USA

\section{J. Junewick $\cdot$ S. K. Culver}

Department of Radiology, Spectrum Health Hospitals,

Grand Rapids, MI, USA

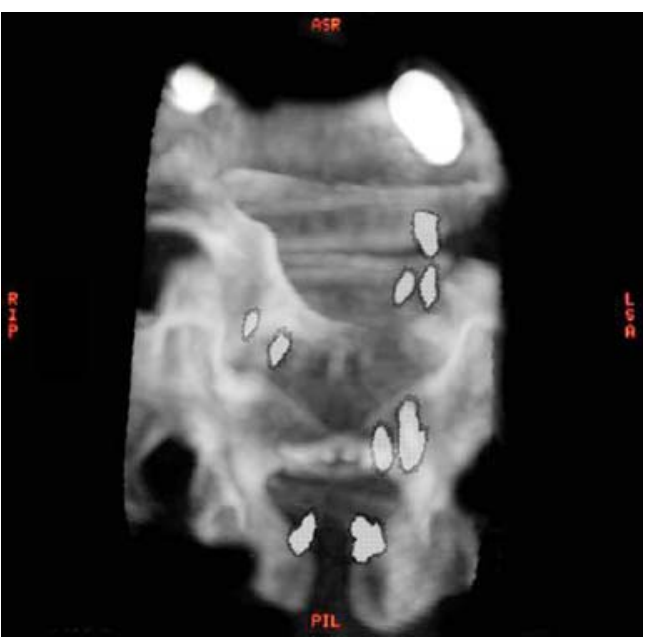

Fig. 2 Volume-rendered CT reconstruction

the nerve root sleeves and caudal recess (Fig. 2). The pedicle screws (white areas) at L5 are evident superiorly.

Arachnoiditis ossificans is a rare chronic meningeal inflammatory process that typically affects adults [1]. The pathogenesis is unknown but thought to be the result of end-stage adhesive arachnoiditis secondary to prior spinal surgery or trauma, subarachnoid hemorrhage or previous lumbar taps/injections [1,2]. Ossified dural plaques can be asymptomatic or might cause pain, myelopathy, radicular signs, sensory disturbance or incontinence $[1,2]$.

\section{References}

1. Chan CC, Lau PY, Sun LK et al (2009) Arachnoiditis ossificans. Hong Kong Med J 15:146-148

2. Faure A, Khalfallah M, Perrouin-Verbe B et al (2002) Arachnoiditis ossificans of the cauda equina: case report and review of the literature. J Neurosurg 97:239-243 